Fernando Berdugo Hurtado ${ }^{1}$ Emilio Guirao Arrabal ${ }^{2}$ Andrés Barrientos Delgado ${ }^{1}$ Antonio José Ruiz Rodriguez'

\section{SARS-CoV-2 infection presenting as acute acalculous cholecystitis}

'Servicio de Aparato Digestivo. Hospital Universitario Clínico San Cecilio. Granada.

${ }^{2}$ Servicio de Enfermedades Infecciosas. Hospital Universitario Clínico San Cecilio. Granada.

Article history

Received: 10 May 2021; Revision Requested: 15 June 2021; Revision Received: 26 August 2021; Accepted: 2 September 2021; Published: 19 November 2021

\section{Sir,}

SARS-CoV-2 infection is commonly related to lung manifestations, the most severe of them being acute respiratory distress syndrome. This infection can sometimes affect many other organs (central nervous system, heart, bowel, etc.) but diarrhea and abdominal pain are the main symptoms from the digestive point of view [1]. Acalculous cholecystitis has been reported as an uncommon complication following severe COVID-19 pneumonia [2]. We report two cases of patients with SARS-CoV-2 infection without any respiratory compromise but being diagnosed of acalculous cholecystitis.

Patient 1 was a 87-year-old woman who came to the emergency department (ED) of our hospital complaining about fever and upper-abdominal pain. No other abdominal symptoms were reported and her respiratory exploration was completely normal. Examination revealed a positive Murphy's sign and her blood test indicated a high white blood cell count and an elevation of acute phase reactants. An abdominal ultrasound revealed gallbladder's wall thickening and a significant amount of perivesicular fluid; without gallstones. Prior to admission, following our hospital protocol, nasopharyngeal swab for RT-PCR for SARS-CoV-2 was performed and yielded a positive result. Endovenous piperacillin-tazobactam was given for 7 days, with good clinical evolution and it was decided not to operate.

Patient 2 was a 62-year-old man who came to the ED because of fever $\left(39,1^{\circ} \mathrm{C}\right)$, nausea and pain located in his right-upper abdominal quadrant. He did not complain about any respiratory symptoms. C-reactive protein, procalcitonin and blood leukocyte count were marked elevated. Blood cultures were finally negative. An abdominal ultrasound was performed, which confirmed an acute cholecystitis and did not visualize any gall-

Correspondence:

Fernando Berdugo Hurtado

Hospital Universitario Clinico San Cecilio.

Av. Innovación s/n. CP 18014. Granada (Spain)

E-mail: fernando_bh94@hotmail.com stones. He also presented positive RT-PCR for SARS-CoV-2 prior to admission. Given the marked improvement and favorable evolution after starting antibiotic therapy with ceftriaxone, it was agreed to perform delayed cholecystectomy.

The two patients did not present any respiratory symptoms upon admission or during their hospital stay. Finally, they were discharged, once the absence of SARS-CoV-2 was confirmed by RT-PCR at 8 and 12 days after admission, respectively.

SARS-type coronaviruses mediate their intracellular entry through the receptor for angiotensin converting enzyme 2 (ACE-2), which is present in various tissues such as the lung, liver or the gallbladder [1-3]. TMPRSS2 co-receptor is also essential for viral entry, and it is widely found in gallbladder tissue $[4,5]$. Some publications have confirmed a relationship between SARS-CoV-2 and acalculous cholecystitis in patients with SARS $\mathrm{CoV}-2$, and some of them have confirmed the presence of the virus by performing RT-PCR in the gallbladder tissue. Ying et al. performed RT-PCR of the bile fluid after percutaneous cholecystostomy in a patient with acute cholecystitis without detecting SARS-CoV-2 [6]. In contrast, Balaphas et al. confirmed by RT-PCR the presence of the virus in the gallbladder wall of a patient with cholecystectomy after an episode of acalculous cholecystitis and COVID-19 infection [7].

All these findings confirm the presence of SARS-CoV-2 in the gallbladder tissue, and the pathogenic mechanism of viral entry mediated by specific viral receptor in the cholangiocytes. Some authors have proposed calling this process "novel coronavirus cholecystitis" [8]. In any case, there are still many gaps in the knowledge of this specific form of presentation of COVID-19.

From April 2020 to February 2021 another 8 patients with lithiasic cholecystitis were admitted to our hospital being RTPCR for SARS-CoV-2 positive at admission. Even when there is a causative relationship between the presence of gallstones and the development of cholecystitis, it is reasonable to think in SARS-CoV-2 as a trigger of the acute inflammatory process. 
The pathological study of the gallbladder would be of interest, but all our cases were treated without surgery.

We cannot establish the true causative role of SARS-CoV-2 in the pathogenesis of cholecystitis in our patients, and SARSCoV-2 infection could also be fortuity. Cholecystitis secondary to SARS-CoV-2 should be more frequent in moderate or severe COVID-19 but a mild disease could also trigger acute viral cholecystitis without severe pulmonary disease, as we hypothesize.

We finally suggest that cholecystitis could be the only manifestation of COVID-19, without associated respiratory symptoms. We propose that SARS-CoV-2 should be ruled out prior to admission by performing nasopharyngeal RT-PCR in every patient with cholecystitis with or without gallstones, in order to stop the spread and adopt specific measures for these patients.

\section{FUNDING}

None to declare

\section{CONFLICTS OF INTEREST}

The authors declare no conflicts of interest

\section{REFERENCES}

1. Gavriatopoulou M, Korompoki E, Fotiou D, Ntanasis-Stathopoulos I, Psaltopoulou T, Kastritis $E_{1}$ et al. Organ-specific manifestations of COVID-19 infection. Clin Exp Med. 2020;20(4):493-506. doi: 10.1007/s10238-020-00648-x

2. Puig G, Giménez-Milà $M$, Campistol $E_{1}$ Caño V, Valcarcel J, Colomina MJ. Development of concomitant diseases in COVID-19 critically ill patients. Rev Esp Anestesiol Reanim. 2021;68(1):37-40. doi: 10.1016/j.redar.2020.09.001.

3. Bruni A, Garofalo E, Zuccalà V, Currò G, Torti C, Navarra G, et al. Histopathological findings in a COVID-19 patient affected by ischemic gangrenous cholecystitis. World J Emerg Surg. 2020;15(1):1-8. doi: 10.1186/s13017-020-00320-5

4. Zhao B, Ni C, Gao R, Wang Y, Yang L, Wei J, et al. Recapitulation of SARS-CoV-2 infection and cholangiocyte damage with human liver ductal organoids. Protein Cell. 2020;11(10):771-5. doi: 10.1007/ s13238-020-00718-6

5. Marjot T, Webb GJ, Barritt AS, Moon AM, Stamataki Z, Wong VW, et al. COVID-19 and liver disease: mechanistic and clinical perspectives. Nat Rev Gastroenterol Hepatol. 2021;0123456789. doi:10.1038/s41575-021-00426-4

6. Ying $M, L u$ B, Pan J, Lu G, Zhou S, Wang D, et al. COVID-19 with acute cholecystitis: A case report. BMC Infect Dis. 2020;20(1):1-4. doi: 10.1186/s12879-020-05164-7

7. Balaphas A, Gkoufa K, Meyer J, Peloso A, Bornand A, McKee TA, et al. COVID-19 can mimic acute cholecystitis and is associated with the presence of viral RNA in the gallbladder wall. J Hepatol. 2020;73(6):1566-8. doi: 10.1016/j.jhep.2020.08.020.
8. Yu X. COVID-19 and Novel Coronavirus Cholecystitis. J Clin Gastroenterol. 2021;55(4):368. doi: 10.1097/MCG.0000000000001488 